\title{
Characterization of mutations in BRCA1/2 and the relationship with clinic-pathological features of breast cancer in a hereditarily high-risk sample of chinese population
}

\author{
MIN FANG ${ }^{1 *}$, LI ZHU $^{2 *}$, HENGYU LI $^{1}$, XIZHOU LI ${ }^{1}$, YANMEI WU ${ }^{1}$, \\ KAINAN WU ${ }^{1}$, JIAN LIN ${ }^{1}$, YUAN SHENG ${ }^{1}$ and YUE YU ${ }^{1}$ \\ ${ }^{1}$ Department of Breast and Thyroid Surgery, Changhai Hospital, The Second Military Medical University, Shanghai 200433; \\ ${ }^{2}$ Department of General Surgery, Chinese People's Liberation Army General Hospital, Beijing 100853, P.R. China
}

Received June 3, 2017; Accepted December 14, 2017

DOI: $10.3892 / \mathrm{ol} .2017 .7717$

\begin{abstract}
The database of BRCA1/2 mutations in Chinese population remains incomplete at present. Therefore, the present study aimed to report specific harmful BRCA1/2 mutations in the Chinese population and discuss the clinicopathological features in mutation carriers. BRCA1/2 germline mutation tests for 71 patients with breast cancer from a hereditarily high-risk Chinese population were performed using next-generation sequencing for identification of deleterious mutations. Furthermore, the clinicopathological features between BRCA1/2 mutation carriers and non-carriers were compared. A total of 13/71 (18.3\%) patients carried a BRCA1 or BRCA2 mutation (7 BRCA1 and 6 BRCA2). The incidence of BRCA1/2 mutation in patients with bilateral breast cancer and patients with family history were 25 , and $32.2 \%$, respectively. Eleven pathogenic or likely pathogenic mutations were identified in 13 patients, among the mutation sites 7 were never reported before in Asian populations. The age at diagnosis of BRCA1/2 mutation carriers was older compared with non-mutation carriers (44.73 vs. 35.39 years; $\mathrm{P}=0.001)$ in this cohort. BRCA $1 / 2$ deleterious mutation carriers had a significantly lower chance of human epidermal growth factor receptor-2 (Her-2) positive status $(\mathrm{P}=0.010)$, higher tumor grade at diagnosis $(\mathrm{P}=0.009)$, higher probability to have a family history $(\mathrm{P}=0.016)$ and older age at diagnosis. Estrogen receptor (ER) and progesterone receptor
\end{abstract}

Correspondence to: Dr Yue Yu or Professor Yuan Sheng, Department of Breast and Thyroid Surgery, Changhai Hospital, The Second Military Medical University, 168 Changhai Road, Shanghai 200433, P.R. China

E-mail: dr_yuyue@163.com

E-mail: sshengyyuan@163.com

*Contributed equally

Key words: breast neoplasms, BRCA1, BRCA2, clinic-pathological, Chinese population
(PR) status were significantly different between BRCA1, and BRCA2 mutation carriers $(\mathrm{P}=0.007)$. The current interpretation of BRCA1/2 status can only explain a small part of hereditary high-risk breast cancer. However, BRCA1/2 gene testing should still be recommended for women with a family history of breast cancer, as well as patients with breast cancer with specific pathologic types, which may be useful to make appropriate clinical decisions for treatment and prevention.

\section{Introduction}

BRCA mutations occur frequently in breast cancer, which is a disease with considerable incidence in the Chinese population. Approximately $90 \%$ of hereditary breast cancers, which accounts for $5-10 \%$ of breast cancer, is related to BRCA1/2 mutations (1,2). BRCA1 and BRCA2 are located on 17q21 and $13 q 12$, respectively, and have been widely accepted as the most important tumor suppressor genes associated with breast cancer (3-5).

Next-generation sequencing (NGS) technology offers a better choice over conventional BRCA1/2 mutation screening by providing additional information of non-coding regions and producing accurate variant results $(6,7)$. The targeted sequencing strategy for both BRCA1 and BRCA2 frequently used currently are promising for characterizing BRCA1/2 mutation in a large population due to the decrease of costs in recent years.

Mutations of the BRCA genes and their associations with clinic-pathological features were reported in several studies (8-11). However, the status of BRCA1/2 mutation in Chinese population, including the incidence of gene mutation, founder mutation and clinic-pathological characteristics, still remains uncertain. In addition, breast cancer cluster regions (BCCRs) have recently been identified in both BRCA1 and BRCA2 based on large sample sets (12). BCCRs were considered to be associated with an increased likelihood of breast cancer compared to ovarian cancer (12). However, the correlation between the mutation locus of BRCA1/2 and tumor characteristics in the Chinese population remains to be obscure. 
In this study, we performed gene testing in 71 hereditarily high-risk breast cancer patients, aiming at reporting the specific BRCA1/2 mutation patterns in Chinese population and discovering the clinic-pathological features of BRCA1/2-related breast cancer.

\section{Materials and methods}

Inclusion criteria. In this study, patients that were pathologically diagnosed with breast cancer and treated in Changhai Hospital Affiliated to Second Military Medical University between May 2015 and May 2016 were screened for BRCA1/2 germline mutation. The present study was approved by Shanghai Changhai Hospital Ethics Committee.

The inclusion criteria were: i) Patients diagnosed with breast cancer before the age of 50, with at least one first- or second-degree relatives diagnosed with breast cancer before the age of 50 or ovarian cancer at any age; or ii) patients diagnosed with bilateral breast cancers and the first diagnosis was made at age no more than 50; or iii) patients diagnosed with breast cancer at any age with at least two first- or second-degree relatives diagnosed with breast cancer or ovarian cancer at any age; or iv) patients diagnosed with breast cancer before age of 35; or v) patients with one or more first- or second-degree relatives diagnosed with male breast cancer; or vi) patients with both breast cancer and ovarian cancer.

Clinical and pathological data including age, sex, tumor type, lymph node status, immuno-histological characteristics and the family history of breast cancer were collected through medical records or telephone interviews.

Gene testing. For each patient, whole blood sample of $5 \mathrm{ml}$ was extracted, and DNA was isolated from mononuclear blood cells using Qiagen DNeasy Blood \& Tissue kit according to the manufacturer's instruction.

The DNA library was prepared according to the Illumina standard procedure: $1 \mu \mathrm{g}$ of genomic DNA was digested with a Biorupter contactless automatic ultrasonic disrupter (Diagenod) to 200-bp fragments, which were then amplified using KAPA HiFi DNA Polymerase after gene modification. The concentration of the sample was measured by Qubit 3.0 Fluorometer (Invitrogen; Thermo Fisher Scientific, Inc., Waltham, MA, USA) and the size of the insert fragment was tested by Agilent 2100 Bioanalyzer (Agilent Technologies, Inc., Santa Clara, CA, USA).

The exon library was prepared according to the Roche NimbleGen SeqCap EZ Choice standard procedure: Pooling hybridization of 12 to 16 DNA fragments was done, followed by target area capture, and the target fragment was enriched by LM-PCR using 1X KAPA HiFi Hot Start Ready Mix. The size of the insert fragment was detected by Agilent 2100 Bioanalyzer and the quantification of the library was tested by qPCR. Finally, PE100 sequencing was performed with the Illumina HiSeq 2500.

Mutation classification. Carriers with pathogenic/likely pathogenic BRCA1/2 mutations were analyzed in this study as deleterious mutations. Pathogenic mutations were defined as: i) Nonsense mutations generating a premature termination codon; ii) large frame deletions; and iii) mutations in the transcription regulatory regions that are expected to influence the expression of mutant allele. In addition, mutations that were considered as pathogenic/likely pathogenic by the Breast Cancer Information Core Committee or that were classified as pathogenic/likely pathogenic by published evidence were also included. During analysis of clinic-pathological features among different BCCRs, people with nonsynonymous single nucleotide mutations were also enrolled.

Statistical analysis. All statistical analyses were performed with SPSS 22.0 software (IBM SPSS, Armonk, NY, USA). Differences between groups in categorical data were analyzed with Chi-square test with continuity correction or Fisher's exact test. Continuous variables were analyzed with t-test. $\mathrm{P}<0.05$ was considered to indicate a statistically significant difference.

\section{Results}

In this study, BRCA1/2 germline mutations were tested in 71 hereditarily high-risk Chinese population with breast cancer, including 8 patients $(11.3 \%)$ diagnosed with bilateral breast cancer. Deleterious BRCA1/2 mutation was found in 13 patients (18.3\%), among which 7 had BRCA1 mutations and 6 had BRCA 2 mutations. Furthermore, the incidence of BRCA1/2 mutation in patients with bilateral breast cancer and patients with family history were 25 and $32.2 \%$, respectively. There were two duplicate mutations on BRCA1 and BRCA2, both from the same family. Frameshift mutation (8/13) was the predominant type, followed by splice site mutation $(2 / 13)$, nonsense mutation (2/13) and nonsense mutation (1/13). Complementary DNA position and resulting amino acid change of each mutation can be found in Fig. 1. Clinical and pathological characteristics of BRCA1/2 mutation carries were listed in Table I.

In this study, we investigated the correlation of clinic-pathological features of breast cancer between BRCA1/2 mutation carriers and non-carriers (Table II) and between BRCA1 and BRCA2 mutations carriers as well (Table III). We also identified the difference in tumor features among people with mutations in different BCCRs (In BRCA1, BCCRs are located at c. 179 to c. 505 , c. 4328 to c. 4945 , c.5261 to c. 5563 , respectively; while in BRCA2, BCCRs are located at c.1 to c.596, c.772 to c.1806, c.7394 to c.8904, respectively) (12). We have also detected novel BCCRs that were not reported previously, which would influence the patient's age at diagnosis of breast cancer.

The clinical and demographic features of enrolled patients were listed in Table II. The average patient age at diagnosis was older in BRCA1/2 carriers than non-carriers (44.73 vs. 35.39 years, $\mathrm{P}=0.001$ ). No difference was found between two groups in terms of tumor size and lymph node status. However, the tumor grade at diagnosis of BRCA1/2 carriers was much higher than non-carriers $(\mathrm{P}=0.009)$. BRCA1/2 carriers were more likely to have a family history than non-carriers $(66.7 \%$ vs. $32.8 \%, \mathrm{P}=0.016)$. In addition, no correlation between mutation locus and clinic-pathological features nor novel BCCRs were found. 
Table I. Clinical and pathological characteristics of BRCA1/2 mutation carriers.

\begin{tabular}{|c|c|c|c|c|}
\hline Gene & Mutation & $\begin{array}{c}\text { Protein } \\
\text { expression }\end{array}$ & $\begin{array}{c}\text { Clinical } \\
\text { manifestations (age) }\end{array}$ & Family history \\
\hline \multirow[t]{7}{*}{ BRCA1 } & c. $3442 \mathrm{delG}$ & E1148fs & $\mathrm{BC}, 52$ years; OC, 42 years & Daughter, BC, 34 years \\
\hline & c. 3442 delG & E1148fs & BC, 34 years & Mother, BC, 52 years; Mother, OC, 42 years \\
\hline & c. $485 \_486 \mathrm{del}^{\mathrm{a}}$ & V162fs & BC, 35 years & No family history \\
\hline & c. $212 \mathrm{G}>\mathrm{A}$ & $\mathrm{R} 71 \mathrm{~K}$ & BC, 44 years & Mother, OC, 54 years; $M$ aunt, OC, 50 years \\
\hline & c. $4676-1 \mathrm{G}>\mathrm{T}^{\mathrm{a}}$ & E1559_Splice & $\mathrm{BC}, 34$ years & Mother, BC, 50 years \\
\hline & c. $5278-1 G>C^{a}$ & I1760_Splice & BBC, 44 and 49 years & No family history \\
\hline & c. $3626 \mathrm{~T}>\mathrm{G}^{\mathrm{a}}$ & L1209X & BBC, 42 and 49 years & No family history \\
\hline \multirow[t]{6}{*}{ BRCA2 } & c. $.5753 \mathrm{delA}^{\mathrm{a}}$ & H1918fs & BC, 59 years & Sister, BC, 45 years; $M$ cousin, BC, 37 years \\
\hline & c. $.5753 \mathrm{delA}^{\mathrm{a}}$ & H1918fs & BC, 37 years & Mother, BC, 45 years; $M$ aunt, BC, 59 years \\
\hline & $\begin{array}{l}\text { c.8400_8402delTT } \\
\text { TinsAAAA }\end{array}$ & 2800_2801del & $\mathrm{BC}, 34$ years & No family history \\
\hline & c. $3883 \mathrm{C}>\mathrm{T}^{\mathrm{a}}$ & Q1295X & BC, 53 years; OC, 58 years & No family history \\
\hline & c. $.5495 \mathrm{delC}^{\mathrm{a}}$ & S1832fs & BC, 75 years & Sister, BC, 70 years \\
\hline & c.2806_2809delAAAC & K936fs & $\mathrm{BC}, 30$ years & No family history \\
\hline
\end{tabular}

$\mathrm{BC}$, breast cancer; $\mathrm{BBC}$, bilateral breast cancer; OC, ovarian cancer; $\mathrm{M}$, maternal. ${ }^{\mathrm{a}}$ Not previously reported in Chinese population with BRCA-associated breast cancer.

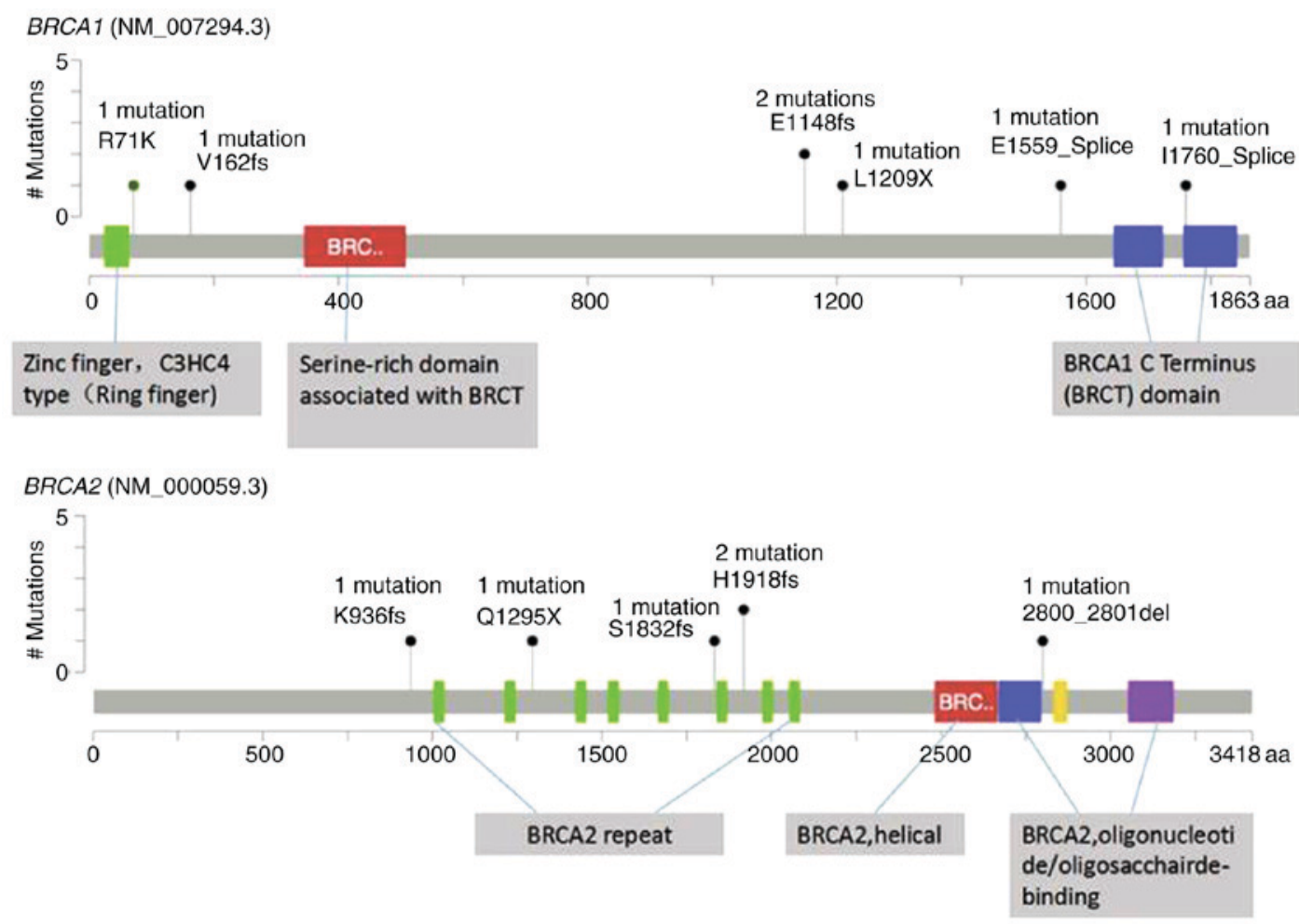

Figure 1. Germline pathogenic/likely pathogenic mutations in BRCA1/2. The total number of mutations identified and resulting acid change of each mutation is presented by a lollipop plot. BRCT, BRCA1 C-terminal domain.

Histologically, the most common type of breast cancer in both group was infiltrating ductal carcinoma (86.7 vs. $89.0 \%$, $\mathrm{P}=1.000$ ). However, there is no difference in histological type between two groups. Positive Her2 status was less frequently seen in BRCA1/2 carriers than non-carriers (6.7 vs. $42.2 \%, \mathrm{P}=0.010$ ). Similarly, no difference in ER and PR status was found between groups. Triple negative (ER, PR and Her2 negative) ratio was mildly higher in BRCA1/2 carriers (46.7 vs. $20.3 \%, \mathrm{P}=0.075$ ).

The correlation between ER, PR and Her2 positivity and BRCA1/2 mutation status was analyzed in Table III with Fisher's exact test. ER and PR positivity was quite different between BRCA1 and BRCA2 mutation carriers (22.2 
Table II. Correlation of clinicopathological features of breast cancer between BRCA1/2 mutation carriers and non-carriers.

\begin{tabular}{|c|c|c|c|c|}
\hline \multirow[b]{2}{*}{ Characteristic } & \multicolumn{2}{|c|}{ BRCA1/2 mutation } & \multirow[b]{2}{*}{ P-value } & \multirow[b]{2}{*}{ OR $(95 \% \mathrm{CI})$} \\
\hline & Carriers $(\mathrm{N}=15)$ & $\begin{array}{l}\text { Non-carriers } \\
\quad(\mathrm{N}=64)\end{array}$ & & \\
\hline Age at diagnosis (years) $($ mean $+\mathrm{SD}) /(\mathrm{n}, \%)$ & $44.7 \pm 12.0$ & $35.4 \pm 8.6$ & 0.023 & $0.138(0.027-0.701)$ \\
\hline$\leq 50$ & $11(73.3)$ & & $61(95.3)$ & \\
\hline$>50$ & $4(26.7)$ & & $3(4.7)$ & \\
\hline Age at menarche (years) $($ mean $+\mathrm{SD})$ & $14.9 \pm 2.2$ & $14.6 \pm 1.6$ & $0.542^{\mathrm{b}}$ & \\
\hline Age at first pregnancy (years) (mean $+\mathrm{SD})$ & $25.0 \pm 3.1$ & $24.8 \pm 3.1$ & $0.399^{\mathrm{b}}$ & \\
\hline BMI $\left(\mathrm{kg} / \mathrm{m}^{2}\right)^{\mathrm{a}}(\mathrm{n}, \%)$ & & & 0.912 & $1.382(0.338-5.653)$ \\
\hline$\leq 25$ & $10(76.9)$ & $41(70.7)$ & & \\
\hline$>25$ & $3(23.1)$ & $17(29.3)$ & & \\
\hline Family history $(\mathrm{n}, \%)$ & & & 0.016 & $4.095(1.241-13.510)$ \\
\hline Yes & $10(66.7)$ & $21(32.8)$ & & \\
\hline No & $5(33.3)$ & $43(67.2)$ & & \\
\hline Tumor localizationa (n, \%) & & & 0.973 & $0.635(0.113-3.571)$ \\
\hline Unilateral & $11(84.6)$ & $52(89.7)$ & & \\
\hline Bilateral & $2(15.4)$ & $6(10.3)$ & & \\
\hline \multicolumn{5}{|l|}{ Histological type (n, \%) } \\
\hline Ductal & $13(86.7)$ & $57(89.0)$ & 1.000 & $0.798(0.148-4.296)$ \\
\hline Lobular & $1(6.7)$ & $1(1.6)$ & 0.826 & $4.500(0.265-76.381)$ \\
\hline Other & $1(6.7)$ & $6(9.4)$ & 1.000 & $0.690(0.077-6.207)$ \\
\hline Grade at diagnosis $(\mathrm{n}, \%)$ & & & 0.009 & $0.182(0.054-0.606)$ \\
\hline I-II & $7(46.7)$ & $53(82.8)$ & & \\
\hline III & $8(53.3)$ & $11(17.2)$ & & \\
\hline \multicolumn{5}{|l|}{ Tumor size (n, \%) } \\
\hline $\mathrm{T} 1$ & $9(60)$ & $37(57.8)$ & 1.000 & $1.095(0.384-3.443)$ \\
\hline $\mathrm{T} 2$ & $6(40)$ & $20(31.3)$ & 0.731 & $1.467(0.460-4.680)$ \\
\hline $\mathrm{T} 3$ & $0(0)$ & $7(10.9)$ & 0.403 & - \\
\hline Lymph nodes status (n, \%) & & & 0.763 & $0.833(0.254-2.731)$ \\
\hline+ & $5(33.3)$ & $24(37.5)$ & & \\
\hline- & $10(66.7)$ & $40(62.5)$ & & \\
\hline $\mathrm{ER}(\mathrm{n}, \%)$ & & & 0.753 & $0.834(0.270-2.580)$ \\
\hline+ & $8(53.3)$ & $37(57.8)$ & & \\
\hline- & $7(46.7)$ & $27(42.2)$ & & \\
\hline $\operatorname{PR}(\mathrm{n}, \%)$ & & & 0.902 & - \\
\hline+ & $8(53.3)$ & $33(51.6)$ & & \\
\hline- & $7(46.7)$ & $31(48.4)$ & & \\
\hline Her2 $(\mathrm{n}, \%)$ & & & 0.010 & $0.098(0.012-0.790)$ \\
\hline+ & $1(6.7)$ & $27(42.2)$ & & \\
\hline- & $14(93.3)$ & $37(57.8)$ & & \\
\hline Triple negative (n, \%) & & & 0.075 & $3.433(1.052-11.206)$ \\
\hline Yes & $7(46.7)$ & $13(20.3)$ & & \\
\hline No & $8(53.3)$ & $51(79.7)$ & & \\
\hline
\end{tabular}

${ }^{a}$ The statistics were cases of patients; ${ }^{b}$ t-test; +, positive; -, negative. BRCA, breast cancer susceptibility gene; BMI, body mass index; ER, estrogen receptor; PR, progesterone receptor; OR, odds ratio; CI, confidence interval; SD, standard deviation.

vs. $100.0 \%, \mathrm{P}=0.007)$. Furthermore, ER and PR statuses were identical in each patient between two groups. On the other hand, Her2 positivity status was similar between two groups (11.1 vs. $0.0 \%, \mathrm{P}=1.000)$. 
Table III. Correlation between ER, PR and Her2 positivity and BRCA1/2 mutation status.

\begin{tabular}{lccc}
\hline & \multicolumn{2}{c}{ Mutation carriers } & \\
\cline { 2 - 3 } Characteristic & BRCA1 n=9 & BRCA2 n=6 & P-value \\
\hline ER (n, \%) & & & 0.007 \\
+ & $2(22.2)$ & $6(100.0)$ & \\
- & $7(77.8)$ & $0(0)$ & \\
PR (n, \%) & & & 0.007 \\
+ & $2(22.2)$ & $6(100.0)$ & \\
- & $7(77.8)$ & $0(0)$ & \\
Her2 (n, \%) & & & 1.000 \\
+ & $1(11.1)$ & $0(0)$ & \\
- & $8(88.9)$ & $6(100.0)$ & \\
\hline
\end{tabular}

+ , positive; -, negative; BRCA, breast cancer susceptibility gene; $\mathrm{ER}$, estrogen receptor; $\mathrm{PR}$, progesterone receptor; OR, odds ratio; $\mathrm{CI}$, confidence interval.

\section{Discussion}

Mutations in several genes have been proved to be correlated with the pathogenesis of breast cancer, including p53, PTEN, CDH1, STK11, MLH1, MSH2, MSH6, PMS2, BRCA1 and BRCA2 (13). Many studies have reported the assessment and management of familial breast cancer risk based on family history or high-risk breast cancer susceptibility alleles (14). BRCA1 and BRCA2 are considered to be the two major tumor suppressor genes that are most closely related to familial breast cancer (15). In this study, pathogenic/likely pathogenic mutations of BRCA1/2 were identified and differences in clinic-pathological features of breast cancer between BRCA1/2 mutation carriers and non-carriers were analyzed in hereditarily high-risk Chinese patients. The association between BRCA1 and BRCA2 mutations was also studied.

In this study, a total of 11 deleterious BRCA $1 / 2$ mutations were found in 13 patients (there are two repeat mutation sites: BRCA1: c.3442delG and BRCA2: c.5753delA), among which 6 mutations were located on BRCA1 and 5 on BRCA2 loci. Four (BRCA1: c. 3442delG and c.212G>A; BRCA2: c.8400_8402del3ins4 and c.2806_2809delAAAC) out of the 11 mutations have been reported in Asian populations (16-19). The other 7 (63.6\%) mutations identified in this study, i.e., BRCA1: c.485_486del; c.4676-1G $>$ T; c.5278-1G $>$ T and c.3626T $>$ G; BRCA2: c.5753delA; c.3883C $>$ T and c.5495delC, have not been reported in any Asian population previously. Two recent studies on Chinese population with large sample numbers have reported the rates of novel BRCA1/2 mutations to be 41.4 and $40.0 \%$, respectively $(19,20)$. This indicates that the spectrum of BRCA1/2 mutation in the Chinese population is quite different from that in the Western population, although the database of BRCA1/2 mutation in Chinese population is not yet complete. Two of the eight newly identified mutations (BRCA1: c.3626T $>\mathrm{G}$ and BRCA2: c. 3883C $>\mathrm{T}$ ) were nonsense mutations, which result in a premature stop codon and consequently a truncated, incomplete, and usually nonfunctional protein product.

Up until now, most data of BRCA1/2 mutations associated with high risk for hereditary breast cancer were derived from non-Asian cohorts (21). Some pilot studies also reported the unique pattern of BRCA1/2 mutations for hereditary breast cancer patients in China $(18,22)$. Thus, it is of high necessity to profile large Chinese hereditary breast cancer cohorts so as to accurately describe the Chinese-specific variants. Our study demonstrated an efficient approach of characterizing mutations in hereditary breast cancer using NGS in a small number of Chinese patients.

BRCA1/2 mutation rate varies widely in different populations. As is reported in a study including 5,931 Chinese women with breast cancer, the mutation rate was $16.9 \%$ in familial breast cancers, $5.2 \%$ in early-onset breast cancers, and $2.0 \%$ in sporadic breast cancers, respectively (19). In another study based on NGS analyses, the mutation rate was $0.38 \%$ in heathy Chinese controls (20). In our study, the mutation rate was $18.3 \%$ in the hereditary high-risk patients, which was significantly higher than that in sporadic breast cancer group. It implicates that people with hereditary high risk are more likely to carry BRCA $1 / 2$ mutation. However, a large proportion of patients with familial breast cancer did not present specific harmful mutations in BRCA1/2. This may be attributed to various reasons: Firstly, the current NGS cannot fully identify the functions of variants of uncertain significance (VUS), single nucleotide polymorphism (SNP) and the interaction between multi-genes during the pathogenesis of hereditary breast cancer; Secondly, in addition to BRCA1/2, many other genes are associated with the onset of breast cancer. The BRCA1/2 mutation-based risk management depends a lot on the accurate interpretation of the specific mutation detected. In the clinical context, VUS in BRCA2 was more difficult to identify compared to that in BRCA1 $(23,24)$. All of the 6 BRCA1 mutations detected in our study were identified as pathogenic while only 1 in 5 BRCA2 mutations was filtered as likely pathogenic according to ClinVar and BRCA mutation database. One feasible way to reduce the number of VUS would be integrating more sequencing data from different clinical centers into the public databases.

Previous studies have demonstrated that family history, age at diagnosis and race are predicting factors for the probability of an individual to carry a BRCA1/2 germline mutation. It is reported that there is a $45-80 \%$ lifetime breast cancer risk in BRCA1/2 mutation carriers (25). In fact, for women carrying BRCA mutations, the risk of developing breast and ovarian cancer increases by $10-15 \%$ annually after the age of 40 (26). The median ages at diagnosis of breast cancer in BRCA1 and BRCA2 mutation carriers are 39.9 and 42.8 years, respectively (12). In other words, BRCA1/2 gene mutations have a limited effect on the pathogenesis of early-onset breast cancer (diagnosed at and before the age of 35). In our study, we found that patient with a younger age at diagnosis was more likely to be a BRCA1/2 non-carrier rather than a carrier (44.73 vs. 35.39 years, $\mathrm{P}=0.001)$. This may be partly explained by the fact that patients selected in this study were in a hereditarily high-risk population with a relatively young age. Therefore, women with specific characteristics should be recommended for a genetic screening. BRCA1/2 mutation carriers identified 
may thereby benefit from lifestyle modification, intensive screening, chemoprevention or risk-reducing surgery (27).

The association between BRCA and ER, PR and Her2 status remains complicated and controversial. Previous studies have shown that the BRCA1 gene can inhibit the transcriptional activity of ERs in human breast and prostate cancer cell lines (28). As a result, nearly $70 \%$ of BRCA1-associated breast cancer have negative ER expression whereas BRCA2-associated cancers are mainly ER positive $(8,29)$. Sanford et al reported that the incidence of BRCA1/2 mutation is similar in patients with hormone receptor (HR)-positive breast cancer and Her2-negative breast cancer (30). BRCA1-related breast cancer is known to have different clinicopathological features from non-BRCA1-related cancer in several studies. Most BRCA1-related breast cancers have low expression of ER, PR and Her2, hence there is a much higher rate of Triple negative breast cancer (TNBC) $(31,32)$. On the other hand, the immunophenotype of BRCA2-related breast cancer is often luminal with overexpression of ER and PR, which is similar to non-BRCA cancer or sporadic cancers (33). As is reported in Hispanic patients of Mexican origin, $72 \%$ of BRCA1/2 mutation carriers were diagnosed with breast cancer at ages $<50$ years, and $61 \%$ were TNBC with a significantly higher BMI (34). They also reported that the ER status was quite different between patients with BRCA1 and BRCA2 mutations, with ER positivity predominately seen in BRCA2 mutation carriers, which is consistent with our findings. In addition, BRCA1/2 mutation carriers are more likely to be Her2 negative $(\mathrm{P}=0.010)$, which was confirmed by two studies on the Chinese population $(19,20)$. However, high incidence of BRCA1/2 mutation was not found in ER or PR negative patients in this study. Furthermore, we find that BRCA1/2 mutation carriers tend to have a higher tumor grade at diagnosis $(\mathrm{P}=0.009)$, which is in line with previous literature $(8,35-37)$. Zhang et al reported a lymph node positivity rate of $34.1 \%$ in BRCA1/2 mutation carriers (19), which is similar to our result $(33.3 \%)$. Furthermore, on-going clinical trials have shown that BRCA mutation-associated tumors tend to be sensitive to the targeted drugs, e.g., poly(ADP-ribose) polymerase (PARP) inhibitors (38). Moreover, BRCA1 mutation carriers may benefit from anthracycline-taxane-containing regimens (39). Therefore, it is essential for Her2-negative patients with higher tumor grade to undergo genetic testing, which may guide future clinical treatment and prognosis assessment.

No significant difference between BCCRs and clinicpathological features of the patients. A possible explanation would be that BCCRs may affect the risk of breast cancer but have a negligible effect on tumor characteristics.

Considering the retrospective single-center nature of the study, the bias may not be ignorable and further studies with larger sample size and other regional groups are warranted. Therefore, these results should be interpreted cautiously.

In conclusion, the current understanding of the BRCA $1 / 2$ mutation pattern can only explain a small part of patients with hereditarily high-risk breast cancer. BRCA1/2 gene mutations have a limited effect on the pathogenesis of early-onset breast cancer. However, BRCA1/2 testing should still be recommended for women with a family history of breast cancer, as well as breast cancer patients with specific pathologic types.
Such genetic testing may be useful to make appropriate clinical decisions for the treatment and prevention of breast cancer.

\section{References}

1. Palmero EI, Alemar B, Schüler-Faccini L, Hainaut $P$, Moreira-Filho CA, Ewald IP, Santos PK, Ribeiro PL, Oliveira CB, Calvez-Kelm FL, et al: Screening for germline BRCA1, BRCA2, TP53 and CHEK2 mutations in families at-risk for hereditary breast cancer identified in a population-based study from Southern Brazil. Genet Mol Biol 39: 210-222, 2016.

2. Ford D, Easton DF, Stratton M, Narod S, Goldgar D, Devilee P, Bishop DT, Weber B, Lenoir G, Chang-Claude J, et al: Genetic heterogeneity and penetrance analysis of the BRCA1 and BRCA2 genes in breast cancer families. The breast cancer linkage consortium. Am J Hum Genet 62: 676-689, 1998.

3. Hall JM, Lee MK, Newman B, Morrow JE, Anderson LA, Huey B and King MC: Linkage of early-onset familial breast cancer to chromosome 17q21. Science 250: 1684-1689, 1990.

4. Wooster R, Neuhausen SL, Mangion J, Quirk Y, Ford D, Collins N, Nguyen K, Seal S, Tran T, Averill D, et al: Localization of a breast cancer susceptibility gene, BRCA2, to chromosome 13q12-13. Science 265: 2088-2090, 1994.

5. Miki Y, Swensen J, Shattuck-Eidens D, Futreal PA, Harshman K, Tavtigian S, Liu Q, Cochran C, Bennett LM, Ding W, et al: A strong candidate for the breast and ovarian cancer susceptibility gene BRCA1. Science 266: 66-71, 1994.

6. Ozcelik H, Shi X, Chang MC, Tram E, Vlasschaert M, Di Nicola N, Kiselova A, Yee D, Goldman A, Dowar M, et al: Long-range PCR and next-generation sequencing of BRCA1 and BRCA2 in breast cancer. J Mol Diagn 14: 467-475, 2012.

7. Chin EL, da Silva C and Hegde M: Assessment of clinical analytical sensitivity and specificity of next-generation sequencing for detection of simple and complex mutations. BMC Genet 14: 6 , 2013.

8. Veronesi A, de Giacomi C, Magri MD, Lombardi D, Zanetti M, Scuderi C, Dolcetti R, Viel A, Crivellari D, Bidoli E and Boiocchi M: Familial breast cancer: Characteristics and outcome of BRCA 1-2 positive and negative cases. BMC Cancer 5: 70, 2005.

9. Musolino A, Bella MA, Bortesi B, Michiara M, Naldi N Zanelli P, Capelletti M, Pezzuolo D, Camisa R, Savi M, et al: BRCA mutations, molecular markers, and clinical variables in early-onset breast cancer: A population-based study. Breast 16: 280-292, 2007.

10. Tung N, Miron A, Schnitt SJ, Gautam S, Fetten K, Kaplan J, Yassin Y, Buraimoh A, Kim JY, Szász AM, et al: Prevalence and predictors of loss of wild type BRCA1 in estrogen receptor positive and negative BRCA1-associated breast cancers. Breast Cancer Res 12: R95, 2010.

11. Atchley DP, Albarracin CT, Lopez A, Valero V, Amos CI, Gonzalez-Angulo AM, Hortobagyi GN and Arun BK: Clinical and pathologic characteristics of patients with BRCA-positive and BRCA-negative breast cancer. J Clin Oncol 26: 4282-4288, 2008.

12. Rebbeck TR, Mitra N, Wan F, Sinilnikova OM, Healey S, McGuffog L, Mazoyer S, Chenevix-Trench G, Easton DF, Antoniou AC, et al: Association of type and location of BRCA1 and BRCA2 mutations with risk of breast and ovarian cancer. JAMA 313: 1347-1361, 2015.

13. Shiovitz S and Korde LA: Genetics of breast cancer: A topic in evolution. Ann Oncol 26: 1291-1299, 2015.

14. Trainer AH, Thompson E and James PA: BRCA and beyond: A genome-first approach to familial breast cancer risk assessment. Discov Med 12: 433-443, 2011.

15. Paul A and Paul S: The breast cancer susceptibility genes (BRCA) in breast and ovarian cancers. Front Biosci (Landmark Ed) 19: 605-618, 2014.

16. Sugano K, Nakamura S, Ando J, Takayama S, Kamata H, Sekiguchi I, Ubukata M, Kodama T, Arai M, Kasumi F, et al: Cross-sectional analysis of germline BRCA1 and BRCA2 mutations in Japanese patients suspected to have hereditary breast/ovarian cancer. Cancer Sci 99: 1967-1976, 2008.

17. Kim H, Cho DY, Choi DH, Choi SY, Shin I, Park W, Huh SJ, Han SH, Lee MH, Ahn SH, et al: Characteristics and spectrum of BRCA1 and BRCA2 mutations in 3,922 Korean patients with breast and ovarian cancer. Breast Cancer Res Treat 134: 1315-1326, 2012. 
18. Kim YC, Zhao L, Zhang H, Huang Y, Cui J, Xiao F, Downs B and Wang SM: Prevalence and spectrum of BRCA germline variants in mainland Chinese familial breast and ovarian cancer patients. Oncotarget 7: 9600-9612, 2016.

19. Zhang J, Sun J, Chen J, Yao L, Ouyang T, Li J, Wang T, Fan Z, Fan T, Lin B and Xie Y: Comprehensive analysis of BRCA1 and BRCA2 germline mutations in a large cohort of 5931 Chinese women with breast cancer. Breast Cancer Res Treat 158: 455-462, 2016.

20. Lang GT, Shi JX, Hu X, Zhang CH, Shan L, Song CG, Zhuang ZG, Cao AY, Ling H, Yu KD, et al: The spectrum of BRCA mutations and characteristics of BRCA-associated breast cancers in china: Screening of 2,991 patients and 1,043 controls by next-generation sequencing. Int J Cancer 141: 129-142, 2017.

21. Blazer KR, Slavin T and Weitzel JN: Increased reach of genetic cancer risk assessment as a tool for precision management of hereditary breast cancer. JAMA Oncol 2: 723-724, 2016.

22. Cao WM, Gao Y, Yang HJ, Xie SN, Ding XW, Pan ZW, Ye WW and Wang XJ: Novel germline mutations and unclassified variants of BRCA1 and BRCA2 genes in Chinese women with familial breast/ovarian cancer. BMC Cancer 16: 64, 2016.

23. Spearman AD, Sweet K, Zhou XP, McLennan J, Couch FJ and Toland AE: Clinically applicable models to characterize BRCA1 and BRCA2 variants of uncertain significance. J Clin Oncol 26: 5393-5400, 2008.

24. Kurian AW, Hare EE, Mills MA, Kingham KE, McPherson L, Whittemore AS, McGuire V, Ladabaum U, Kobayashi Y, Lincoln SE, et al: Clinical evaluation of a multiple-gene sequencing panel for hereditary cancer risk assessment. J Clin Oncol 32: 2001-2009, 2014

25. Antoniou A, Pharoah PD, Narod S, Risch HA, Eyfjord JE, Hopper JL, Loman N, Olsson H, Johannsson O, Borg A, et al: Average risks of breast and ovarian cancer associated with BRCA1 or BRCA2 mutations detected in case series unselected for family history: A combined analysis of 22 studies. Am J Hum Genet 72: 1117-1130, 2003.

26. King MC, Marks JH and Mandell JB; New York Breast Cancer Study Group: Breast and ovarian cancer risks due to inherited mutations in BRCA1 and BRCA2. Science 302: 643-646, 2003

27. Paluch-Shimon S, Cardoso F, Sessa C, Balmana J, Cardoso MJ, Gilbert F and Senkus E; ESMO Guidelines Committee: Prevention and screening in BRCA mutation carriers and other breast/ovarian hereditary cancer syndromes: ESMO clinical practice guidelines for cancer prevention and screening. Ann Oncol 27 (Suppl 5): v103-v110, 2016.

28. Fan S, Ma YX, Wang C, Yuan RQ, Meng Q, Wang JA, Erdos M, Goldberg ID, Webb P, Kushner PJ, et al: Role of direct interaction in BRCA1 inhibition of estrogen receptor activity. Oncogene 20: 77-87, 2001.

29. Lakhani SR, Reis-Filho JS, Fulford L, Penault-Llorca F, van der Vijver M, Parry S, Bishop T, Benitez J, Rivas C, Bignon YJ, et al: Prediction of BRCA1 status in patients with breast cancer using estrogen receptor and basal phenotype. Clin Cancer Res 11: 5175-5180, 2005 .
30. Sanford RA, Song J, Gutierrez-Barrera AM, Profato J, Woodson A, Litton JK, Bedrosian I, Albarracin CT, Valero V and Arun B: High incidence of germline BRCA mutation in patients with ER low-positive/PR low-positive/HER-2 neu negative tumors. Cancer 121: 3422-3427, 2015.

31. van der Groep P, van der Wall E and van Diest PJ: Pathology of hereditary breast cancer. Cell Oncol (Dordr) 34: 71-88, 2011.

32. Mavaddat N, Barrowdale D, Andrulis IL, Domchek SM, Eccles D, Nevanlinna H, Ramus SJ, Spurdle A, Robson M, Sherman $\mathrm{M}$, et al: Pathology of breast and ovarian cancers among BRCA1 and BRCA2 mutation carriers: Results from the consortium of investigators of modifiers of BRCA1/2 (CIMBA). Cancer Epidemiol Biomarkers Prev 21: 134-147, 2012.

33. Keeney MG, Couch FJ, Visscher DW and Lindor NM: Non-BRCA familial breast cancer: Review of reported pathology and molecular findings. Pathology 49: 363-370, 2017.

34. Nahleh Z, Otoukesh S, Dwivedi AK, Mallawaarachchi I, Sanchez L, Saldivar JS, Cataneda K and Heydarian R: Clinical and pathological characteristics of hispanic BRCA-associated breast cancers in the American-Mexican border city of $\mathrm{El}$ Paso, TX. Am J Cancer Res 5: 466-471, 2014.

35. Zhang J, Pei R, Pang Z, Ouyang T, Li J, Wang T, Fan Z, Fan T, Lin B and Xie Y: Prevalence and characterization of BRCA1 and BRCA2 germline mutations in Chinese women with familial breast cancer. Breast Cancer Res Treat 132: 421-428, 2012.

36. Kwong A, Wong LP, Wong HN, Law FB, Ng EK, Tang YH, Chan WK, Suen DT, Choi C, Ho LS, et al: Clinical and pathological characteristics of Chinese patients with BRCA related breast cancer. Hugo J 3: 63-76, 2009.

37. Chen W, Pan K, Ouyang T, Li J, Wang T, Fan Z, Fan T, Lin B, $\mathrm{Lu} \mathrm{Y}$, You W and Xie Y: BRCA1 germline mutations and tumor characteristics in Chinese women with familial or early-onset breast cancer. Breast Cancer Res Treat 117: 55-60, 2009.

38. Gelmon KA, Tischkowitz M, Mackay H, Swenerton K, Robidoux A, Tonkin K, Hirte H, Huntsman D, Clemons M, Gilks B, et al: Olaparib in patients with recurrent high-grade serous or poorly differentiated ovarian carcinoma or triple-negative breast cancer: A phase 2, multicentre, open-label, non-randomised study. Lancet Oncol 12: 852-861, 2011.

39. Arun B, Bayraktar S, Liu DD, Gutierrez Barrera AM, Atchley D, Pusztai L, Litton JK, Valero V, Meric-Bernstam F, Hortobagyi GN and Albarracin C: Response to neoadjuvant systemic therapy for breast cancer in BRCA mutation carriers and noncarriers: A single-institution experience. J Clin Oncol 29: 3739-3746, 2011.

This work is licensed under a Creative Commons Attribution-NonCommercial-NoDerivatives 4.0 International (CC BY-NC-ND 4.0) License. 